\title{
Linear alkybenzene sulfonate and alkyl sulfate biodegradation in laboratory and field activated sludge systems
}

\author{
T. G. Ellis ${ }^{1}$, X. Huang ${ }^{2}$ \& S. K. Kaiser ${ }^{3}$ \\ ${ }^{1}$ Department of Civil, Construction and Environmental Engineering, \\ Iowa State University, Ames, Iowa, USA \\ ${ }^{2}$ ERM, Inc., Exton, Pennsylvania, USA \\ ${ }^{3}$ Biomerieux, Inc., Hazelwood, Missouri, USA
}

\begin{abstract}
The fate and biodegradation of two xenobiotic compounds, linear alkylbenzene sulfonate (LAS) and alkyl sulfate (AS), were investigated in laboratory and field activated sludge systems. Two $1-\mathrm{L}$ porous pot $(65 \mu$ stainless steel mesh) reactors were fed synthetic wastewater $(200 \mathrm{mg} \mathrm{COD} / \mathrm{L}$ including $2 \mathrm{mg} / \mathrm{L} \mathrm{LAS}$ and $1 \mathrm{mg} / \mathrm{L}$ alkyl sulfate) to evaluate the influence of specific operating conditions (i.e. hydraulic retention time, HRT, and solids retention time, SRT) on the measured rate of biodegradation. The reactors were operated in parallel under a constant SRT of $10 \mathrm{~d}$, and HRTs of 2, 4, 6, and $12 \mathrm{~h}$. Subsequently, the reactors were operated under a constant HRT of $6 \mathrm{~h}$, and SRTs of 3,6, 10, and $15 \mathrm{~d}$. The extant kinetic parameters obtained from respirometric experiments suggest that the HRT had little impact on the measured kinetic parameters $\left(\hat{\mu}=0.14 \pm 0.06 \mathrm{~h}^{-1}, \mathrm{~K}_{\mathrm{S}}=0.4 \pm 0.3 \mathrm{mg} \mathrm{COD} / \mathrm{L}, \mathrm{Y}=0.67 \pm 0.02 \mathrm{mg}\right.$ biomass COD formed/mg LAS COD utilized and $\hat{\mu}=0.0 .25 \pm 0.01 \mathrm{~h}^{-1}$, $\mathrm{K}_{\mathrm{S}}=0.35 \pm 0.07 \mathrm{mg} \mathrm{COD} / \mathrm{L}$, and yield $=065 \pm 0.02 \mathrm{mg}$ biomass COD formed/mg AS COD utilized) at a constant SRT of $10 \mathrm{~d}$. The SRT had a more noticeable effect on the measured biodegradation kinetics (e.g., Y increased from $0.50 \pm 0.08$ to $0.66 \pm 0.05 \mathrm{mg} / \mathrm{mg}$ and $0.49 \pm 0.07$ to $0.61 \pm 0.07$ when the SRT increased from 3 to $10 \mathrm{~d}$ at a constant HRT of $6 \mathrm{~h}$ for LAS and AS, respectively). Extant kinetics for LAS biodegradation were measured in the field at three activated sludge wastewater treatment plants operated at different conditions. The field results were similar to the results from laboratory systems operated to simulate the field conditions. Using the COD fraction to calculate the competent biomass concentration, the field measured extant kinetic parameters were used to accurately predict effluent concentrations within $2 \%$ on average at one plant and within $4 \mu \mathrm{g} / \mathrm{L}$ at two other plants. Day to day predictions were not as accurate, possibly due to the non-steady-state nature of the field systems.
\end{abstract}

Keywords: linear alkylbenzene sulfonate, alkyl sulphate, biodegradation, kinetics, competent biomass, respirometry, activated sludge. 


\section{Introduction}

Surface active agents, or surfactants, are components of widely used household laundry detergents, household cleaners, shampoos, cosmetics, antistatic agents, textile aids, and textile softeners. Linear alkyl benzene sulfonate (LAS) was introduced in 1965 as a biodegradable alternative to non-biodegradable branchchained alkyl benzene sulfonates (ABS) and since has become the common anionic surfactant in commercial detergent formulations. For example, worldwide use of LAS in 1997 exceeded 2 million metric tons and AS use was approximately half that of AS [1]. Trehy et al. [2] reported environmental LAS concentrations in the influent $(3.0-7.7 \mathrm{mg} / \mathrm{L})$ and effluent $(0.003-0.086 \mathrm{mg} / \mathrm{L})$ of the activated sludge process from 10 U.S. wastewater treatment plants. Influent concentrations in European WWTPs are estimated at 13.2 and $4.7 \mathrm{mg} / \mathrm{L}$ for LAS and AS, respectively [3]. Kaiser et al. [4] reported LAS concentrations in the influent to domestic wastewater treatment plants typically ranges from 1 $\mathrm{mg} / \mathrm{L}$ to $5 \mathrm{mg} / \mathrm{L}$. Krueger et al. [5] observed that LAS was readily biodegraded in activated sludge systems and the LAS had a half-life of 1-2 days. Others [2, 6-8] have reported on the complexity in the measurement of LAS biodegradation intermediates which caused difficulties in evaluating biodegradation. van Ginkel [9] demonstrated the importance of SRT for maintaining sufficient surfactantdegrading microorganisms in wastewater treatment plants, while Temmink and Klapwijk [3] suggest that the influent concentration and adsorption to biomass were important in describing LAS removal. In a previous study [4] using porous pots to simulate activated sludge, effluent concentrations of LAS were found to be a function of influent concentrations when the HRT was less than $10 \mathrm{~h}$. Federle et al. [7] determined that primary and complete biodegradation of LAS were best described by a first-order approach with the first-order rate constants of $0.50-0.53 \mathrm{~h}^{-1}$. The kinetics and removal of LAS in municipal activated sludge treatment systems have been previously studied [4] using laboratory continuousflow activated sludge systems and radio-labeled LAS. First-order rate constants of LAS removal were determined during this study, but the methods to determine the kinetic constants were labor-intensive and time consuming. Zhang et al. [10] found that the biodegradation rate of anionic surfactants over a range of concentrations (i.e., sub-and supra-critical micelle concentrations) followed Monod kinetics.

The main objective of the present study was to determine the efficacy of extant respirometry to provide accurate measurements of the biodegradation kinetic parameters of surfactants in laboratory and field activated sludge systems. The goal was to be able to use the resulting kinetics to describe, and eventually to predict, the fate of LAS in activated sludge systems. The extant kinetic parameters of LAS were measured over a range of operating conditions at several activated sludge wastewater treatment plants and in laboratory porous pot reactors simulating activated sludge. 


\section{Materials and methods}

The laboratory apparatus consisted of two porous pot reactors (stainless steel mesh pore size of $65 \mu$ ) with a working volume of 1-L. They were operated in parallel as continuous stirred tank reactors (CSTRs) for a period of one year. Sludge wastage was performed automatically three times per day using a timer or once per day manually to maintain the desired SRT. Surfactant LAS was a mixture of LAS homologs with $96.8 \% \mathrm{C}_{12}$ LAS, dodecyl benzene sulfonatesodium salt, in liquid form with $51.5 \%$ active fraction. For all kinetic measurements, an injection concentration of $2 \mathrm{mg} / \mathrm{L}$ as COD was used. $1 \mathrm{mg} / \mathrm{L}$ LAS was found to be equivalent to $2.7 \mathrm{mg} / \mathrm{L}$ as COD by the standard COD test. The fraction of the biomass involved in the biodegradation of LAS was assumed to be equal to the fraction of energy (COD) supplied to the culture by LAS [1113]. Consequently, a competent biomass fraction of $2.7 \%$ was used for the laboratory experiments. A similar competent biomass fraction (2.9\%) was determined for the field experiments. Phosphate buffer was added to the biomass sample to maintain the $\mathrm{pH}$ at approximately 6.8 to 7.0 during the respirometer tests [14].

Respirometric tests were used as a surrogate measurement of LAS and AS disappearance in batch kinetic tests as described previously [15]. Samples were placed in $250 \mathrm{~mL}$ sealed respirometric vessels with constant temperature water jackets (Tudor Glass Co., Belvedere, SC). The dissolved oxygen (DO) concentration was measured by a DO meter (Model 3550, Yellow Springs, CO), and the DO probes were fitted with high sensitive membranes. The temperature was controlled by a water bath at $25 \pm 0.1^{\circ} \mathrm{C}$. The initial dissolved oxygen concentration was elevated to approximately $16-18 \mathrm{mg} / \mathrm{L}$ using pure oxygen to prevent oxygen from becoming limiting during the entire respirometric response. The biomass was continuously stirred using a magnetic stir bar. When a linear decrease in DO was observed, a low concentration ( $2 \mathrm{mg} / \mathrm{L}$ as COD) injection of LAS or AS was made to the respirometric vessel, resulting in a low initial substrate to biomass concentration ratio $\left(S_{0}: X_{0}\right)$ ensuring that the test was a measure of the extant kinetics of the biomass [16]. The DO response data was collected continuously at a sampling frequency of $10 \mathrm{~Hz}$ through a data acquisition board installed in a personal computer. The resulting data file was averaged to provide a DO measurement every 2 to 4 seconds and normalized to subtract the background endogenous oxygen uptake rate. The biodegradation response was modeled in an Excel $^{\mathrm{TM}}$ spreadsheet, and the kinetic parameters were estimated by nonlinear regression using a fourth-order Runge-Kutta approximation of the Monod equation .

Preliminary experiments to ascertain the reliability and reproducibility of the extant technique for measuring surfactant kinetics included experiments to determine the effect of the initial substrate concentration, the effect of the initial DO concentration, and the effect of re-injecting LAS to the same biomass sample. The tests were conducted with biomass from the Boone Water Pollution Control Plant (WPCP), Boone, Iowa. Grab samples of the influent to Boone 
plant were collected and measured by liquid chromatography/mass spectroscopy (LC/MS) to determine the LAS and AS influent concentrations.

To evaluate the validity of using synthetic wastewater for the laboratory studies, a side-by-side comparison of porous pot reactors fed synthetic and raw wastewater was performed. Extant tests were run to determine whether the kinetic parameters in the two reactors were comparable. The raw wastewater was collected from the Boone WPCP and diluted to $200 \mathrm{mg} / \mathrm{L}$ as COD. The composition of the synthetic wastewater is shown in Table 1. Both wastewaters were fed at a concentration of $200 \mathrm{mg} \mathrm{COD} / \mathrm{L}$, and $2 \mathrm{mg} / \mathrm{L}$ LAS $(5.4 \mathrm{mg} / \mathrm{L}$ as $\mathrm{COD})$ and $1 \mathrm{mg} / \mathrm{L}$ AS $(2.2 \mathrm{mg} / \mathrm{L}$ as COD) were added to the synthetic wastewater. It was assumed that the actual wastewater contained a similar amount of LAS and AS (which was confirmed by subsequent analysis). The reactors were operated at room temperature $22 \pm 2{ }^{\circ} \mathrm{C}$. To maintain a diverse microbial consortium, $5 \mathrm{ml}$ of mixed liquor from a local municipal wastewater treatment plant was added to the reactors every other day. This addition represented less than $2 \%$ of the feed COD to the reactors and less than $2 \%$ of the porous pot mixed liquor concentration at all operating conditions.

Table 1: $\quad$ Composition of synthetic wastewater fed to porous pot reactors.

\begin{tabular}{|c|c|c|c|}
\hline Macronutrients & Conc., mg/L & Micronutrients & Conc., $\mu \mathrm{g} / \mathrm{L}$ \\
\hline Urea & 37.6 & $\mathrm{NiSO}_{4} \cdot 6 \mathrm{H}_{2} \mathrm{O}$ & 100 \\
\hline Nutrient broth & 60.0 & $\mathrm{ZnCl}_{2}$ & 62 \\
\hline Lauric acid & 7.0 & $\mathrm{CuCl}_{2} \cdot 2 \mathrm{H}_{2} \mathrm{O}$ & 159 \\
\hline Potato starch & 6.0 & $\mathrm{CoCl}_{2} \cdot 6 \mathrm{H}_{2} \mathrm{O}$ & 18 \\
\hline Non-fat dried & 60.0 & $\mathrm{MnSO}_{4} \cdot \mathrm{H}_{2} \mathrm{O}$ & 22 \\
\hline milk & 10.0 & EDTA & 74 \\
\hline Dietary fiber & 20.0 & $\mathrm{~K}_{2} \mathrm{MoO}_{2}$ & 5 \\
\hline Sodium acetate & 10.0 & $\mathbf{n}_{2} \mathrm{~N}^{2} \mathrm{U}_{4}$ & \\
\hline $\mathrm{Na}\left(\mathrm{HCO}_{3}\right)$ & 3.0 & & \\
\hline $\mathrm{K}_{3} \mathrm{PO}_{4} \cdot \mathrm{H}_{2} \mathrm{O}$ & 0.5 & & \\
\hline $\mathrm{FeSO}_{4} \cdot 7 \mathrm{H}_{2} \mathrm{O}$ & 2.0 & & \\
\hline LAS & 1.0 & & \\
\hline AS & & & \\
\hline
\end{tabular}

After it was determined that synthetic wastewater was an acceptable substitute for real wastewater, two porous pot reactors were fed synthetic wastewater to evaluate the influence of HRT and SRT on the biodegradation responses. The reactors were operated in parallel under a constant SRT of $10 \mathrm{~d}$, and HRTs of 2, 4, 6, and $12 \mathrm{~h}$. Subsequently, the reactors were operated under a constant of HRT of $6 \mathrm{~h}$, and SRTs of 3, 6, 10, and $15 \mathrm{~d}$. An additional porous pot operating condition was run at $18 \mathrm{~h}$ HRT and $30 \mathrm{~d}$ SRT to simulate the operating conditions at the Boone WPCP, an extended aeration activated sludge plant with an HRT of approximately $18 \mathrm{~h}$ and SRT in the range of $24-30 \mathrm{~d}$. Additional field tests were conducted at the Iowa City Wastewater Treatment 
Plant (WWTP), a conventional activated sludge plant with an HRT of approximately $4-6 \mathrm{~h}$ and SRT of approximately $6 \mathrm{~d}$.

\section{Results and discussion}

LAS and AS concentrations were measured in the influent to the Boone WPCP, and the results indicated a range of LAS and AS concentrations from $1-5 \mathrm{mg} / \mathrm{L}$ as shown in Table 2. These findings are similar to the results reported by Kaiser et al., 1997. From this table it can be seen that $\mathrm{C}_{12}$ LAS accounted for about $20 \%$ of the total LAS concentration. The $\mathrm{C}_{12}$ homolog was used as the representative test compound for this study. To estimate of the competent fraction of LAS degrading biomass, an average LAS concentration of $2.86 \mathrm{mg} / \mathrm{L}$ (7.72 $\mathrm{mg} \mathrm{COD} / \mathrm{L}$ ) and influent COD concentration of $265 \mathrm{mg} / \mathrm{L}$ were used to calculate a COD fraction of $2.9 \%$. Therefore, since the biomass obtained $2.9 \%$ of its energy from LAS, it was assumed that $2.9 \%$ of the biomass had the capacity to degrade LAS $[12,13]$. Similarly, the competent fraction of degrading biomass in the porous pot reactors was estimated as $2.7 \%$, since LAS contributed $2.7 \%$ of the feed COD.

Table 2: $\quad$ LAS and AS concentrations in the influent to the Boone WPCP.

\begin{tabular}{ccccccccc}
\hline \hline $\begin{array}{c}\text { Sample } \\
\text { (day) }\end{array}$ & $\begin{array}{c}\mathrm{C}_{10} \mathrm{LAS} \\
\mathrm{mg} / \mathrm{L}\end{array}$ & $\begin{array}{c}\mathrm{C}_{11} \mathrm{LAS} \\
\mathrm{mg} / \mathrm{L}\end{array}$ & $\begin{array}{c}\mathrm{C}_{12} \mathrm{LAS} \\
\mathrm{mg} / \mathrm{L}\end{array}$ & $\begin{array}{c}\text { Total LAS } \\
\mathrm{C}_{10-14} \\
\mathrm{mg} / \mathrm{L}\end{array}$ & $\begin{array}{c}\mathrm{C}_{12} \mathrm{AS} \\
\mathrm{mg} / \mathrm{L}\end{array}$ & $\begin{array}{c}\mathrm{C}_{13} \mathrm{AS} \\
\mathrm{mg} / \mathrm{L}\end{array}$ & $\begin{array}{c}\mathrm{C}_{14} \mathrm{AS} \\
\mathrm{mg} / \mathrm{L}\end{array}$ & $\begin{array}{c}\text { Total AS } \\
\mathrm{C}_{12-15} \mathrm{mg} / \mathrm{L}\end{array}$ \\
\hline $\begin{array}{c}1 \\
2\end{array}$ & 0.74 & 0.54 & 0.18 & 1.46 & 0.22 & 0.16 & $<0.05$ & 0.38 \\
3 & 1.1 & 0.82 & 0.44 & 2.36 & 0.42 & 0.16 & 0.12 & 0.7 \\
$4(1)$ & 1.08 & 0.94 & 0.56 & 2.58 & 0.50 & 0.22 & 0.16 & 0.88 \\
$4(2)$ & 1.76 & 1.88 & 0.9 & 4.72 & 2.22 & 1.04 & 0.70 & 4.06 \\
$4(3)$ & 1.86 & 1.68 & 1.16 & 4.92 & 1.70 & 0.86 & 0.68 & 3.48 \\
\hline $\begin{array}{c}\text { avg } \\
\text { s.d. }\end{array}$ & $1.2 \pm 0.5$ & $1.0 \pm 0.6$ & $0.6 \pm 0.4$ & $2.9 \pm 1.6$ & $0.9 \pm 0.9$ & $0.4 \pm 0.4$ & $0.3 \pm 0.3$ & $1.6 \pm 1.7$ \\
\hline \hline
\end{tabular}

Experiments to test the influence of a range of HRTs ( $2 \mathrm{~h}, 4 \mathrm{~h}, 6 \mathrm{~h}$ and $12 \mathrm{~h})$ with a constant SRT of $10 \mathrm{~d}$ on the biodegradation kinetics of LAS were performed. Subsequently, the experiments to test the influence of a range of SRTs $(3 \mathrm{~d}, 6 \mathrm{~d}, 10 \mathrm{~d}, 15 \mathrm{~d})$ with a constant HRT of $6 \mathrm{~h}$ were conducted. The results of the extant biodegradation tests are shown in Table 3.

From Table 3 it can be seen that the measured kinetic parameters were fairly constant when the SRT was maintained. There was some variability at the short HRT conditions, possibly due to the difficulty in maintaining steady-state 
conditions (e.g., plugging of the stainless steel screen and subsequent cleaning may caused the true SRT/HRT to deviate slightly from short circuiting and./or loss of solids). Similar results were observed by Kaiser et al. [4] where effluent concentration of LAS remained constant and relatively independent of influent concentrations at higher HRTs, but varied at lower HRTs. At the long SRT conditions, there was a slight decrease in the $\hat{\mu}$ and $\mathrm{K}_{\mathrm{S}}$ values for LAS, possibly indicative of low velocity, high affinity enzyme systems at these conditions. The evidence for this, however, was not strong. In pure culture studies, Sokol [1719] and Sokol and Migiro [20] observed a much more pronounced decrease in $\hat{\mu}$ values for cultures grown at increasingly long SRTs. A similar decrease was not observed for the measured kinetic parameters for AS.

Table 3: Extant kinetic parameters in porous pot reactors at various HRT and SRT conditions.

\begin{tabular}{|c|c|c|c|c|c|c|c|}
\hline \multirow{2}{*}{$\begin{array}{l}\text { HRT } \\
\text { (SRT) }\end{array}$} & \multicolumn{3}{|l|}{ LAS } & \multicolumn{3}{|l|}{ AS } & \multirow{2}{*}{$\begin{array}{l}\mathrm{VSS}, \\
\mathrm{mg} / \mathrm{L}\end{array}$} \\
\hline & $\hat{\mu}, \mathrm{h}^{-1}$ & $\begin{array}{l}\mathrm{K}_{\mathrm{s}}, \mathrm{mg} \\
\mathrm{COD} / \mathrm{L}\end{array}$ & $\begin{array}{l}\mathrm{Y}, \mathrm{mg} / \mathrm{mg} \\
\text { as COD }\end{array}$ & $\hat{\mu}, \mathrm{h}^{-1}$ & $\begin{array}{l}\mathrm{K}_{\mathrm{s}}, \mathrm{mg} \\
\mathrm{COD} / \mathrm{L}\end{array}$ & $\begin{array}{l}\mathrm{Y}, \mathrm{mg} / \mathrm{mg} \\
\text { as COD }\end{array}$ & \\
\hline $2(10)$ & $0.18 \pm 0.07$ & $0.8 \pm 0.9$ & $0.68 \pm 0.10$ & $0.26 \pm 0.01$ & $0.2 \pm 0.1$ & $0.68 \pm 0.04$ & 3574 \\
\hline $4(10)$ & $0.20 \pm 0.05$ & $0.5 \pm 0.3$ & $0.68 \pm 0.07$ & $0.23 \pm 0.09$ & $0.3 \pm 0.2$ & $0.69 \pm 0.07$ & 2233 \\
\hline $6(10)$ & $0.08 \pm 0.03$ & $0.2 \pm 0.1$ & $0.66 \pm 0.05$ & $0.25 \pm 0.07$ & $0.4 \pm 0.3$ & $0.61 \pm 0.06$ & 1283 \\
\hline $12(10)$ & $0.09 \pm 0.02$ & $0.2 \pm .02$ & $0.65 \pm 0.05$ & $0.26 \pm 0.01$ & $0.5 \pm 0.0$ & $0.61 \pm 0.07$ & 794 \\
\hline $6(3)$ & $0.05 \pm 0.01$ & $0.2 \pm 0.1$ & $0.50 \pm 0.08$ & $0.17 \pm 0.02$ & $0.2 \pm 0.2$ & $0.49 \pm 0.07$ & 260 \\
\hline $6(6)$ & $0.08 \pm 0.02$ & $0.1 \pm 0.1$ & $0.65 \pm 0.04$ & $0.20 \pm 0.06$ & $0.2 \pm 0.1$ & $0.52 \pm 0.07$ & 461 \\
\hline $6(10)$ & $0.08 \pm 0.03$ & $0.2 \pm 0.1$ & $0.66 \pm 0.06$ & $0.25 \pm 0.07$ & $0.4 \pm 0.3$ & $0.61 \pm 0.07$ & 1283 \\
\hline $6(15)$ & $0.06 \pm 0.01$ & $0.1 \pm 0.1$ & $0.69 \pm 0.03$ & * & * & $0.49 \pm 0.09$ & 1550 \\
\hline $18(15)$ & $0.02 \pm 0.01$ & $0.1 \pm 0.0$ & $0.68 \pm 0.10$ & $0.21 \pm 0.12$ & $0.6 \pm 0.1$ & $0.47 \pm 0.03$ & 980 \\
\hline $6(30)$ & $0.07 \pm 0.02$ & $0.1 \pm 0.1$ & $0.64 \pm 0.11$ & $0.29 \pm 0.06$ & $1.3 \pm 0.3$ & $0.52 \pm 0.08$ & 2760 \\
\hline $18(30)$ & $0.03 \pm 0.01$ & $0.1 \pm 0.1$ & $0.48 \pm 0.13$ & * & * & $0.43 \pm 0.15$ & 2250 \\
\hline
\end{tabular}

*Unique estimates were not obtainable for these tests due to parameter identifiability difficulties. However, the pseudo-first order rate coefficient was determined and was found to be $0.36 \pm 0.09$ and $0.10 \pm 0.02$ for the $6(15)$ and $18(30)$ conditions, respectively.

To evaluate the ability of extant kinetic parameters to predict effluent concentrations in full-scale wastewater treatment plants, field tests were conducted whereby the influent and effluent concentrations of LAS were measured as were the extant kinetic parameters. The method of Ellis and Eliosov [13] was used to estimate the competent biomass concentration by using a calibration period whereby the steady-state mass balance equation [23] and measured kinetic parameters are used to estimate the percent of competent biomass that would result in the measured effluent concentration of LAS. As can be seen from Table 4, the influent COD fraction provided a reasonable estimate of the competent biomass fraction. Consequently, the COD fraction was used for subsequent predictions of effluent concentrations.

Table 5 shows the results of the predictions of effluent LAS concentrations using measured extant kinetic parameters. Since the competent fraction measured during the calibration period was relatively close to the influent COD fraction (Table 4), the influent COD fraction was used to calculate the biomass involved in LAS degradation. 
Table 4: Comparison of influent COD to estimated competent biomass fraction.

\begin{tabular}{|c|c|c|c|c|c|c|c|c|}
\hline $\begin{array}{l}\text { Week } \\
\text { (Day) }\end{array}$ & $\begin{array}{c}\text { Influent } \\
\text { COD } \\
\text { fraction, } \%\end{array}$ & $\begin{array}{c}\text { Effl. } \\
\text { conc., } \\
\mu \mathrm{g} \mathrm{COD} / \mathrm{L}\end{array}$ & $\begin{array}{c}K_{S}, \\
\mathrm{mg} \mathrm{COD} / \mathrm{L}\end{array}$ & $\begin{array}{c}\hat{\mu} \mathrm{X}, \\
\mathrm{mg} \\
\mathrm{COD} /(\mathrm{LXhr})\end{array}$ & $\hat{\mu}, \mathrm{h}^{-1}$ & $\begin{array}{c}\text { Comp. } \\
\text { biomass, } \\
\text { mg } \\
\text { COD/L } 1\end{array}$ & $\begin{array}{c}\text { MLVSS } \\
\mathrm{mg} \\
\mathrm{COD} / \mathrm{L}\end{array}$ & $\begin{array}{c}\text { Comp. } \\
\text { biomass } \\
\text { fraction } \\
\% \\
\end{array}$ \\
\hline 1 & 0.32 & 16 & 0.42 & 6.7 & 0.41 & 16.3 & 2272 & 0.72 \\
\hline 2 & 0.30 & 46 & 0.62 & 7.2 & 0.21 & 34.3 & 2499 & 1.37 \\
\hline 3 & 0.58 & 7 & 1.02 & 6.7 & 0.43 & 15.6 & 2200 & 0.71 \\
\hline 4 & 1.57 & 84 & 1.00 & 6.3 & 0.19 & 34.0 & 1988 & 1.71 \\
\hline $5(1)$ & 2.66 & 57 & 1.34 & 7.5 & 0.36 & 20.8 & 3237 & 0.64 \\
\hline $5(3)$ & 1.60 & 24 & 0.78 & 11.3 & 0.50 & 22.6 & 3209 & 0.70 \\
\hline $5(4)$ & 1.38 & 19 & 1.19 & 12.2 & 0.48 & 25.4 & 3152 & 0.81 \\
\hline$A v \pm$ s.d & $1.13 \pm 0.8$ & $36 \pm 27$ & $0.91 \pm 0.32$ & $8.2 \pm 2.4$ & $0.4 \pm 0.1$ & $24 \pm 7$ & $2650 \pm 535$ & $50.95 \pm 0.42$ \\
\hline
\end{tabular}

$\overline{{ }^{1} \text { A measured } \mathrm{k}_{\mathrm{d}} \text { value of } 0.11 \mathrm{~d}^{-1} \text { was used. }}$

Table 5: Comparison of predicted and measured effluent LAS concentrations at three wastewater treatment plants.

\begin{tabular}{ccc}
\hline \hline $\begin{array}{c}\text { Week } \\
\text { (Day) }\end{array}$ & \multicolumn{2}{c}{ Effluent concentration, $\mu \mathrm{g}$ COD/L } \\
Measured & Predicted $^{2}$ \\
\hline \multicolumn{3}{c}{ Cedar Rapids WPCF } \\
1 & 16 & 98 \\
2 & 46 & 143 \\
3 & 7 & 17 \\
4 & 84 & 15 \\
$5(1)$ & 57 & 32 \\
$5(3)$ & 24 & 9 \\
$5(4)$ & 19 & 15 \\
Ave. \pm s.d. & $43 \pm 16$ & $41 \pm 47$ \\
& Boone WPCP & \\
1 & 3.6 & 9.9 \\
2 & 2.9 & 2.5 \\
$3(1)$ & 2.3 & 7.6 \\
$3(3)$ & 3.9 & 5.8 \\
Ave. \pm s.d. & $2.9 \pm 0.7$ & $6.5 \pm 3.1$ \\
$1^{1}$ & Iowa City WWTP & \\
2 & 5.9 & 13.2 \\
3 & 4.4 & 9.5 \\
4 & 4.0 & 8.8 \\
Ave. \pm s.d. & 3.9 & 6.5 \\
\hline \hline
\end{tabular}

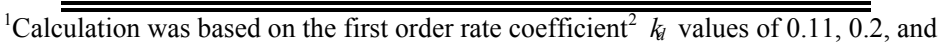
$0.2 \mathrm{~d}^{-1}$ were used for the Cedar Rapids, Boone, and Iowa City plants, respectively.

\section{Conclusion}

The efficacy of the extant respirometric technique to measure the extant kinetics of LAS biodegradation by field and laboratory biomass was demonstrated in this 
study. LAS biodegradation kinetics in laboratory porous pot reactors were independent of whether the reactor was fed synthetic or real wastewater. The influence of HRT on the measured biodegradation kinetics was minimal with the possible exception that the biokinetic parameters were more variable at the low HRT conditions (i.e., when HRT $<6$ h). The SRT had more noticeable effect on the measured biodegradation kinetics (e.g., the Y value for increased from $0.50 \pm$ 0.08 to $0.66 \pm 0.05 \mathrm{mg} / \mathrm{mg}$ and $0.49 \pm 0.07$ to $0.61 \pm 0.07 \mathrm{mg} / \mathrm{mg}$ when the SRT increased from 3 to $10 \mathrm{~d}$ at a constant HRT of $6 \mathrm{~h}$ for LAS and AS, respectively).

The similarity in kinetic parameters between laboratory and field activated sludge systems was apparent from the study. The COD fraction proved to be a reliable indicator of the competent biomass concentration as validated by the calibration of the steady-state model. Extant kinetic parameters predicted average effluent LAS concentrations within $2 \%$ at one plant and within $4 \mu \mathrm{g} / \mathrm{L}$ at two other plants. Day to day predictions were not as close probably due to the non-steady state nature of the full-scale wastewater treatment plants and the limitations of the steady-state model.

\section{Acknowledgements}

The authors thank Bill Bagley and David Lee at the Procter and Gamble Co. for their expertise and assistance in determining LAS concentrations and Dave Mozena at the Boone WPCP and Steven Julius at the Iowa City Wastewater Treatment Plant for their help in collecting mixed liquor samples. This work was funded in part by the Water Environment Research Foundation (98-CTS-3). This manuscript has not been subjected to the Foundation's peer and administrative review and therefore does not necessarily reflect the views of the Foundation, and no official endorsement should be inferred.

\section{References}

[1] Cavalli, L., Clerici, R., Radici, P. \& Valtorta, L. Update on LAB/LAS. Tenside Surfact. Det. 36, pp. 254-258, 1999.

[2] Trehy, M. L, Gledhill, W. E., \&Mieure, J. P., Adamove J. E, Nielsen, A. M., Perkins, H. O., \& Eckhoff, W. S. Environmental monitoring for linear alkylbenzene sulfonates, dialkyltetralin sulfonates and their biodegradation intermediates, Environmental Toxicology and Chemistry, 15, pp. 233-240, 1995.

[3] Temmink, H. \& Klapwijk, B. Fate of linear alkylbenzene sulfonate (LAS) in activated sludge plants. Water Research, 38, pp. 903-912, 2004.

[4] Kaiser, S. K., Guckert, J. B., \& Gledhill, D. W., Comparison of activated sludge microbial communities using biolog $\mathrm{TM}$ microplates, The 2nd International IAWQ Conference on Microorganisms in Activated Sludge and Biofilm Processes, Berkeley, California. July, pp.21-23, 1997.

[5] Krueger, C. J., Radakovich, K. M., Sawyer, T. E., Barber L. B., Smith, R. L., \& Field, J. A. Biodegradation of the surfactant linear Alkylbenzenesulfonate in sewage-Contaminated groundwater: A 
comparison of column experiments and field tracer tests, Environ. Sci. Technol, 32, pp. 3954-3961, 1998.

[6] Crescenzi, C., Corcia, A. D., Marchiori, E., Samperi, R., \& Marcomini, A. Simultaneous determination of alkylbenzenesulfonates and dialkyltetralinsulfonates in water by liquid chromatography, Wat. Res., 30, 722-730, 1996.

[7] Federle, T. W. \& Itrich, N. R. Comprehensive approach for assessing the kinetics of primary and ultimate biodegradation of chemicals in activated sludge: Application to linear alkylbenzene sulfonate, Environ. Sci. Technol., 31, pp. 1178-1184, 1997.

[8] Mampel, J., Hitzler, T., Ritter, A., \& Cook, A. M. Desulfonation of biotransformation products from commercial linear alkylbenzene sulfonates, Environmental Toxicology and Chemistry, 17, pp. 1960-1963, 1998.

[9] van Ginkel, C. G. Complete degradation of xenobiotic surfactants by consortia of aerobic microorganisms, Biodegradation, 7, pp. 151-164, 1996.

[10] Zhang, C., Valsaraj, K. T., Constant, W. D., \& Roy, D. Aerobic biodegradation kinetics of four anionic and nonionic surfactants at suband surpra-critical micelle concentrations (CMCs), Wat. Res., 33, pp. 115-124, 1999.

[11] Blackburn, J. W., Jain, R. K., \& Sayler, G. S. Molecular microbial ecology of naphthalene-degrading genotype in activated sludge. Environ. Sci. Technol., 21, pp. 884, 1987.

[12] Magbanua, B. S. Jr., Poole, L. J., and Grady C. P. L. Jr. Estimation of the competent biomass concentration for the degradation of synthetic organic compounds in an activated sludge culture receiving a multicomponent feed, Wat. Sci. Tech., 38, 55-62, 1998.

[13] Eliosov, B. \& Ellis, T. G. Use of extant kinetic parameters to predict effluent concentrations of specific organic compounds at full scale facilities. Water Environment Research.76, pp. 444-452, 2004.

[14] Ellis, T. G. \& Anselm, C. V., Effect of batch discharges on extant biodegradation kinetics in activated sludge systems. Water Environment Research, 71, pp. 290-298, 1999.

[15] Ellis, T. G., Barbeau, D. S., Smets, B. F., \& Grady, C. P. L. Jr. Respirometric technique for determination of extant kinetic parameters describing biodegradation. Water Environment Research, 68, pp. 917-926, 1996.

[16] Grady, C. P. L., Jr., Smets, B. F., \& Barbeau, D. S. Variability in kinetic parameter estimates: possible causes and a proposed terminology, Wat. Res., 30, pp. 742-748, 1996.

[17] Sokol, W. Oxidation of an inhibitory substrate by washed cells, Biotechnology and Bioengineering, 30, pp. 921-927, 1987.

[18] Sokol, W. Dynamics of continuous stirred-tank biochemical reactor utilizing inhibitory substrate, Biotechnology and Bioengineering, 30, pp. 921-927, 1988. 
[19] Sokol, W. Uptake rate of phenol by Pseudomonas putida grown in unsteady state. Biotechnology and Bioengineering, 32, pp. 1097-1103, 1988.

[20] Sokol, W. \& Migiro, C. L.C. Metabolic responses of microorganism growing on inhibitory substrates in nonsteady state culture, J. Chem. Tech. Biotechnol., 54, pp. 223-229, 1992.

[21] Bielfeldt, A. R. \& Stensel H. D. Evaluation of biodegradation kinetic testing methods and long term variability in biokinetics for BTEX metabolism. Wat. Res., 33, pp. 733-740. 1999.

[22] Ellis T.G., Smets B.F., Magbanua B.S. Jr., and Grady C.P.L. Jr. (1996b) Changes in measured biodegradation kinetics during the long term operation of completely mixed activated sludge (CMAS) reactors. Water Science and Technology, 34, 5/6, 35-42.

[23] Grady, C. P. L. Jr., Daigger, G. T., and Lim, H. C. Biological Wastewater Treatment, $2^{\text {nd }}$ Edition, Marcel Dekker, Inc., New York, NY, 1999. 